\title{
Do acidente médico à responsabilidade civil médica no ordenamento jurídico da República Popular da China
}

From medical malpractices to medical civil liability in the legal system of the People's Republic of China

De los errores médicos a la responsabilidad civil médica en el ordenamiento jurídico de la República Popular de China

RESUMO: Objetivos - observar se o regime do erro médico previsto no Regulamento para o Tratamento de Acidentes Médicos perde ou não a sua utilidade prática a partir da entrada em vigor da Lei de Responsabilidade Civil da República Popular da China que prevê especificamente um regime da responsabilidade pelos danos causados por tratamentos médicos; segundo, ver se a constituição de acidente médico ainda é um pressuposto da responsabilidade civil médica prevista na lei citada; terceiro, ver se ambos os regimes, agora de diferentes diplomas legais, requerem os mesmos requisitos e se cada um destes tem o mesmo âmbito. Metodologia - executaram-se estudos bibliográficos e normativos que se relacionam com os dois regimes. Resultado e conclusão - o regime de acidente médico apenas perde a sua utilidade prática relativa à responsabilidade civil médica, mas ainda se mantém a sua utilidade prática de natureza administrativa. A constituição de acidente médico não é um pressuposto da responsabilidade civil médica prevista na nova lei. Os requisitos para ambos os regimes são o facto ilícito, negligência médica ou culpa, dano, nexo de causalidade e instituição médica e profissionais de saúde como sujeitos, mas alguns destes requisitos têm âmbito diferente, como nas partes relativas à ilicitue, à negligência médica ou culpa e ao dano.

Palavras-chave: Erro médico. Responsabilidade profissional. Dano ao Paciente

ABSTRACT: Objectives - Firstly, to test whether the regime of medical accident regulated by the Regulation on the Handling of Medical Accident loses its practical use since the effectiveness of the Tort Law of the People's Republic of China, which provides for a regime of liability for damages caused by medical treatments; Secondly, evaluate whether the characterization of medical accident is still part of medical civil liability regulated in the Chinese Tort Law ; Thirdly, discuss if both regimes - which now originate from different legal documents - contain the same requirements and the same scope. Methodology were mainly based on bibliography and the investigation of norms related to both regimes. Result and Conclusion - even though the regime that regulates medical accidents loses its practical use regarding the medical civil liability, it still maintains its utility as a practical guide for administration. The existence of medical accident is not a direct need to characterize medical civil liability regulated in the new law. The illicit fact, medical negligence or fault, damage, causality and medical institution and medical staff members as subjects are the requisites of both regimes. Notwithstanding some of them have different

\footnotetext{
${ }^{1}$ Ph.D. Researcher of Faculty of Law of University of Macau. Juridical Consultant and Notary of Macau Health Bureau. Email: manteng.iong@gmail.com
} 
understanding, such as the contents relating to the illegality, to medical negligence or fault and damage.

Keywords: Medical errors. Medical liability. Pacient Harm.

RESUMEN: Objetivos: En primer, observar si el régimen del accidente médico pierde o no su utilidad práctica a partir de la entrada en vigor de la Ley de Responsabilidad Civil de la República Popular de China. La Ley prevé específicamente un régimen de la responsabilidad por los daños causados por tratamientos médicos; en según, evaluar si la constitución de accidente médico sigue siendo un suposición de la responsabilidad civil médica prevista en la ley citada; En tercer, analizar si los dos regímenes, que pertenecen a diferentes diplomas legales, exhiben los mismos requisitos y si cada uno de ellos tiene el mismo alcance. Metodología: se realizaron estudios bibliográficos y normativos que se relacionan con los dos regímenes. Resultado y conclusión: el régimen de accidentes médicos sólo pierde su utilidad práctica relativa a la responsabilidad civil médica, pero sigue siendo de utilidad práctica de carácter administrativo. La caracterización del accidente médico no es un supuesto de la responsabilidad civil médica prevista en la nueva ley. Los requisitos para ambos regímenes son el hecho ilícito, negligencia médica o culpa, daño, nexo de causalidad e institución médica y profesionales sanitarios como sujetos, pero algunos de estos requisitos tienen un ámbito diferente, como en las partes relativas a la ilicitud, la negligencia médica o la culpa y el daño.

Palabras-Ilave: Accidente médico. Responsabilidad médica. Daño al paciente.

\section{Introdução}

No presente ordenamento jurídico da República Popular da China (RPC), o Regulamento para o Tratamento de Acidentes Médicos (Regulation on the Handling of Medical Accident) prevê um regime de acidente médico contendo normas jurídicas de naturezas civil e administrativa. Contudo, a partir de 1 de Julho de 2010, data da entrada em vigor da Lei de Responsabilidade Civil da RPC (Tort Law of the People's Republic of China), esta lei prevê um capítulo específico (Capítulo VII Responsabilidade para Danos Causados pelo Tratamento Médico) contendo disposições jurídicas de natureza civil e, no entanto, não revogou as normas de natureza civil daquele regulamento. Neste contexto, é duvidoso se o referido regulamento ainda tem a sua natureza civil.

Portanto, este artigo, pelos estudos bibliográficos e normativos, destina-se a resolver as questões seguintes: se o regulamento acima mencionado ainda mantém a sua natureza civil? Em caso negativo, se a constituição de um acidente médico ainda é um pressuposto da responsabilidade civil médica prevista na nova lei? Quais são os requisitos da responsabilidade civil médica que a nova lei prevê e, comparando com os requisitos do acidente médico, aqueles requisitos têm o mesmo âmbito destes requisitos? 
Para melhor esclarecimento e resolução das questões supra referidas, este texto segue a seguinte estrutura: primeiro, apresentação relativa à evolução do termo "acidente médico"; segundo, apresenção sobre a mudança do regime de acidente médico ao regime da responsabilidade civil médica, resolvendo-se as primeiras duas questões acima levantadas; por fim, apresentação sobre os requisitos do acidente médico e da responsabilidade civil médica, analisando se ambos os regimes têm os mesmos requisitos e se cada um destes tem o mesmo âmbito.

Com os estudos bibliográficos e normativos realizados, temos as seguintes conclusões: primeira, o Regulamento para o Tratamento de Acidentes Médicos apenas mantém a sua natureza administrativa a partir da entrada em vigor da Lei de Responsabilidade Civil da RPC; segunda, a constituição de um acidente médico não é um pressuposto da responsabilidade civil médica prevista na nova lei; finalmente, por um lado, os requisitos de ambos os regimes são facto ilícito, negligência médica ou culpa, dano, nexo de causalidade e instituição médica e profissionais de saúde como sujeitos, e por outro lado, alguns dos requisitos da responsabilidade civil médica têm âmbito diferente comparando com o âmbito dos mesmos requisitos do acidente médico, como nas partes relativas à ilicitude, à negligência médica ou culpa e ao dano.

\section{Evolução do conceito do "acidente médico" no ordenamento jurídico da RPC}

O conceito do acidente médico apareceu, pela primeira vez, no ordenamento jurídico da RPC a partir de 29 de Junho de 1987, data da entrada em vigor das Medidas para o Tratamento de Acidentes Médicos (Measures for the Handling of Medical Accidents), promulgadas pelo Conselho Estadual da RPC, cujo artigo 2.ำ previa o seguinte:

$\mathrm{O}$ acidente médico previsto nestas Medidas é aquele que, durante o exercício de diagnóstico, tratamento e enfermagem e pela negligência dos profissionais de saúde, causa diretamente a morte, incapacidade ou dano nos tecidos e órgãos de paciente que conduz à disfunção².

Deste conceito podemos retirar que anteriormente se exigiriam como requisitos de acidente médico os seguintes: facto ilícito, negligência médica, dano, causalidade entre o facto ilícito e o dano, e profissional de saúde como sujeito responsável (1).

\footnotetext{
2 Tradução livre.
} 
Esse conceito sofreu uma mudança a partir da entrada em vigor do Regulamento para o Tratamento de Acidentes Médicos (Regulation on the Handling of Medical Accident) em 1 de Setembro de 2002, emitido pelo Conselho Estadual, e passou a ter a redação seguinte:

O termo "acidente médico" mencionado no presente Regulamento deve referir-se àqueles que tenham causado lesão pessoal aos pacientes por negligência de instituição médica ou seus profissionais de saúde nas atividades de tratamentos médicos, pela violação das leis, regulamentos, regras ministeriais sobre tratamento e saúde médica, ou padrões ou convenções de tratamento médico ou enfermagem ${ }^{3}$.

Deste conceito novo podemos entender que se constitui um acidente médico caso sejam cumpridos os seguintes requisitos: facto ilícito, negligência médica, dano, causalidade entre o facto ilícito e o dano, bem como instituição médica e seus profissionais de saúde como sujeitos responsáveis.

Comparando com o conceito anterior, o conceito novo tem um âmbito de aplicação mais abrangente no que se refere ao dano, aos sujeitos responsáveis e à causalidade: por um lado, enquanto o conceito anterior exigia pelo menos a disfunção causada no paciente, o conceito recente exige a ocorrência de dano com menos seriedade, pelo que o dano que não cause disfunção no paciente agora já pode ser um requisito que constitui um acidente médico, caso os outros requisitos deste sejam também cumpridos; por outro lado, os sujeitos responsáveis pelo acidente médico podem ser a instituição médica e os seus profissionais de saúde, em vez de apenas estes últimos, como exigia o conceito anterior; por fim, foi eliminada a palavra "diretamente" do conceito anterior, o que quer dizer que a causalidade é mais larga na sua aplicação do que anteriormente (4).

\section{Do regime de acidente médico ao regime da responsabilidade civil médica}

Antes de 1 de Julho de 2010, data da entrada em vigor da Lei de Responsabilidade Civil da RPC, o Regulamento para o Tratamento de Acidentes Médicos desempenhava um papel muito importante para analisar se um ato médico constituía um acidente médico. Em caso afirmativo, por um lado, a instituição médica poderia ser civilmente responsável pelo dano causado no paciente nos termos dos seus artigos 46.. a 52.. (Capítulo V

\footnotetext{
3 Tradução livre.
} 
Compensações para Acidentes Médicos); por outro lado, a instituição médica e os seus profissionais de saúde que tivessem praticado o ato médico em causa poderiam apanhar sancionamento de natureza administrativa, ao abrigo dos seus artigos 35. a 45. (Capítulo IV Sancionamento e Supervisão Administrativas de Acidentes Médicos) e dos artigos 53.․․ a 59. (Capítulo VI Disposições de Sancionamento). Portanto, a constituição de um acidente médico seria um pressuposto da responsabilidade civil médica e do sancionamento administrativo.

Após a entrada em vigor da Lei de Responsabilidade Civil da RPC, esta lei prevê um capítulo específico relativo à responsabilidade civil médica (Capítulo VII Responsabilidade para Danos Causados pelo Tratamento Médico). Como esta lei não prevê o termo "acidente médico" e, em simultâneo, não revogou o Regulamento para o Tratamento de Acidentes Médicos, surgiu a questão de saber se a constituição de um acidente médico ainda é um pressuposto da responsabilidade civil médica prevista nesta lei. A resposta é negativa. Independentemente de constituição de um acidente médico, desde que haja dano causado no paciente durante a atividade médica, são aplicáveis as disposições previstas no Capítulo VII da Lei de Responsabilidade Civil da RPC (12). Em teoria, apenas quando ambas as partes (o paciente e a instituição médica) requerem ao tribunal a resolução da disputa médica conforme as disposições reguladas no Regulamento para o Tratamento de Acidentes Médicos, o tribunal pode afirmar a responsabilidade civil e a respetiva indemnização nos termos do mesmo regulamento, mas na prática jurisprudencial tal não é possível porque a instituição médica não pode citar as disposições legais no referido regulamento caso o paciente insista em apresentar o seu recurso contencioso conforme a nova lei (12). É evidente que o paciente sempre recusa a aplicação dess regulamento e prefere recorrer à nova lei para apresentar o seu recurso contencioso, porque esta última lei não exige a constituição de um acidente médico que depende dos certos procedimentos de autenticação técnica de acordo com os artigos $20 . .^{\circ}$ a $34 .^{\circ}$ (Capítulo III Autenticação Técnica de Acidentes Médicos). Por conseguinte, o Regulamento para o Tratamento de Acidentes Médicos, nomeadamente os seus artigos 46. a 52.ำ (Capítulo V Compensações para Acidentes Médicos), perde a sua utilidade prática no âmbito da responsabilidade civil médica. É muito estranho que, ao perder essa sua utilidade prática, os artigos 46. a 52. (Capítulo V Compensações para Acidentes Médicos) 
do Regulamento para o Tratamento de Acidentes Médicos não foram revogados pela Lei de Responsabilidade Civil da RPC.

Ora, resta saber se o Regulamento para o Tratamento de Acidentes Médicos ainda tem a sua utilidade prática no âmbito do sancionamento de natureza administrativa. Como a aplicação das sanções administrativas ainda depende da ocorrência de um acidente médico que, por sua vez, depende dos determinados procedimentos de autenticação técnica, é necessário saber, antes de tudo, se o departamento administrativo de saúde pode por sua iniciativa pedir a autenticação técnica de acidentes médicos a qualquer das Associações Locais de Ciência Médica (isto é, entidades responsáveis pela autenticação técnica), para que o mesmo departamento proceda ao sancionamento de natureza administrativa à instituição médica infratora após ter sido qualificado pela associação local um acidente médico.

Ao responder esta pergunta, é necessário conhecer quais são as formas de iniciação de autenticação técnica de acidentes médicos. A autenticação técnica de acidentes médicos pode iniciar-se por três formas: primeira, iniciação pelo departamento administrativo de saúde; segunda, iniciação pelo consentimento de ambas as partes; terceira, iniciação pelo tribunal que entende necessária a autenticação técnica (13). Relativamente à primeira forma, o departamento administrativo de saúde pode, por sua iniciativa, transmitir o caso a qualquer das Associações Locais de Ciência Médica para efeitos de autenticação técnica, depois de ter recebido o relatório da instituição médica sobre atos médicos negligentes graves ou após qualquer das partes ${ }^{4}$ apresentar o seu requerimento de tratamento de disputa médica ao departamento administrativo de saúde local, nos termos do artigo 20. do Regulamento para o Tratamento de Acidentes Médicos. No que concerne à segunda forma, o consentimento de ambas as partes perde a sua utilidade prática porque o paciente prefere recorrer à Lei de Responsabilidade Civil da RPC para a resolução da disputa médica e para o pedido de indemnização por esta lei não exigir a autenticação técnica e a ocorrência de um acidente médico, ao contrário do que sucede no Regulamento para o Tratamento de Acidentes Médicos. No que respeita à terceira forma, a iniciação pelo tribunal também perde a sua utilidade porque o tribunal só

\footnotetext{
4 Como se disse, é evidente que o paciente não apresenta um tal requerimento e prefere recorrer à Lei de Responsabilidade Civil da RPC para a resolução da disputa médica porque esta lei não depende de constituição de um acidente médico.
} 
pode analisar o caso e, entendendo necessário, entregar o caso a qualquer das Associações Locais de Ciência Médica para efeitos de autenticação técnica, quando o paciente apresenta o mesmo caso ao tribunal para efeitos de indemnização de danos causados nos termos do Regulamento para o Tratamento de Acidentes Médicos, mas a verdade é que o paciente prefere apresentar o caso ao tribunal de acordo com a Lei de Responsabilidade Civil da RPC porque esta lei não exige os procedimentos da autenticação técnica e a constituição de um acidente médico.

Pelo exposto, podemos concluir que o Regulamento para o Tratamento de Acidentes Médicos ainda se mantém a sua utilidade prática no âmbito do sancionamento de natureza administrativa, porque o departamento administrativo de saúde local ainda pode, por sua iniciativa, entregar o caso a qualquer das Associações Locais de Ciência Médica para efeitos de autenticação técnica de acidente médico. Ou seja, esse regulamento, mesmo perdendo a sua natureza civil, ainda mantém a sua natureza administrativa.

\section{Requisitos do acidente médico e da responsabilidade civil médica}

Como os regimes do acidente médico e da responsabilidade civil médica, agora ambos regulados pelos diplomas diferentes, dependem dos determinados requisitos, convém analisar se têm os mesmos requisitos e se cada um destes tem o mesmo âmbito.

\section{Do facto ilícito}

Do conceito de acidente médico podemos entender que a ilicitude implica a violação das leis, regulamentos, regras ministeriais sobre tratamento e saúde médica, ou padrões ou convenções de tratamento médico ou enfermagem. No enquadramento jurídico da RPC, as leis sobre tratamento e saúde médica referem-se à Lei sobre Médicos Praticantes da RPC (Law on Practicing Doctors of the People's Republic of China) e à Lei de Administração Farmacêutica da RPC (Pharmaceutical Administration Law of the People's Republic of China); os regulamentos sobre tratamento e saúde médica dizem respeito ao Regulamento para o Tratamento de Acidentes Médicos (Regulation on the Handling of Medical Accident) e ao Regulamento para a Administração de Instituições Médicas (Regulation on the Administration of Medical Institutions); as regras ministeriais sobre tratamento e saúde médica têm relação com as Regras Detalhadas sobre a Implementação do Regulamento para o Tratamento de Acidentes Médicos (Detailed Rules 
on the Implementation of the Regulation on the Handling of Medical Accident) e com as Regras Detalhadas sobre a implementação do Regulamento para a Administração de Instituições Médicas (Detailed Rules on the Implementation of the Regulation on the Administration of Medical Institutions); por fim, os padrões e convenções de tratamento médico ou enfermagem englobam as regras e orientações internas de instituições médicas, bem como as leges artis (5). A ilicitude que o acidente médico exige deve abranger apenas o âmbito supra limitado e não se deve ampliá-lo, porque caso contrário se ampliaria o âmbito de acidente médico e, deste modo, agravaria a sua responsabilidade (9). No entanto, há quem entenda que a violação de tais disposições não implica ilicitude, mas sim a existência de negligência (18). Esta posição não me parece correta porque o que podemos entender é que a ilicitude presume a culpa, não perdendo a sua existência.

No âmbito da responsabilidade civil médica prevista na Lei de Responsabilidade Civil da RPC, a ilicitude implica que durante o diagnóstico e tratamento médico a instituição médica e seus profissionais de saúde violam as obrigações legalmente previstas que protegem os direitos e interesses civis, como o direito à vida, o direito à saúde, direito à integridade física, direito à autodeterminação, direito à privacidade, direito à propriedade, etc. (7) Dizendo de outra forma, a ilicitude tem como consequência a violação de qualquer das obrigações legalmente previstas. Por isso, podemos entender que a ilicitude que a responsabilidade civil médica exige é mais abrangente do que a ilicitude do acidente médico, porque as obrigações legais podem ser várias e não se limitam apenas às disposições relativas ao tratamento e saúde médica, como ocorre na ilicitude do acidente médico ${ }^{5}$.

Existe autor que vai mais longe, negando a ilicitude como um dos requisitos da responsabilidade civil médica (8). Caso se entendesse assim, a instituição médica cujos profissionais de saúde praticam atos médicos lícitos poderia ser responsabilizada pelos danos causados ao paciente. O que não faz nenhum sentido, porque a instituição médica e seus profissionais de saúde só têm obrigação de meio e não obrigação de resultado. Caso contrário, a instituição médica e seus profissionais de saúde promoveria mais a medicina defensiva para que não houvesse qualquer dano causado ao paciente, o que influencia o desenvolvimento ou avanço médico.

\footnotetext{
5 Por exemplo, a obrigação legal de respeitar o direito à autodeterminação do paciente, cuja violação não implica a
} ilicitude do acidente médico porque não se trata da violação de uma disposição relativa ao tratamento e saúde médica. 
Mais se acrescenta que os profissionais de saúde, que violem as leis, regulamentos, regras ministeriais sobre tratamento e saúde médica, ou padrões ou convenções de tratamento médico ou enfermagem, podem atuar por ação ou por omissão, quer no âmbito do acidente médico (5) quer no âmbito da responsabilidade civil médica (7). No que respeita à comissão por omissão, esta só é ilícita quando os profissionais de saúde se sujeitam ao certo dever jurídico e não o cumprem (7).

Por fim, é de salientar que, quer no acidente médico quer na responsabilidade civil médica, o ato médico ilícito deve ocorrer durante a atividade médica, isto é, entre a marcação de consulta e o término de tratamento, bem como dentro da instituição médica, pelo que fora deste âmbito temporal e espacial o que se trata não de acidente médico nem de responsabilidade civil médica, mas sim de prática médica ilícita, o que pode causar responsabilidade civil ou/e criminal em geral (4) (5) (16) (20).

\section{Da negligência médica ou culpa}

No âmbito do acidente médico, como acima esclarecido, só a negligência médica pode ser requisito que constitui o acidente médico. No ordenamento jurídico da RPC, a negligência médica engloba duas formas, a negligência e a negligência excessivamente confiante (4). A primeira forma significa que o ator deveria prever que o seu próprio ato poderia causar danos a outrem, mas que com a negligência não o previu; a segunda forma implica que o ator já previu que o seu próprio ato poderia causar danos a outrem, mas teve confiança excessiva de que pode evitá-los (14) (16).

$\mathrm{Na}$ doutrina chinesa existe uma posição minoritária, entendendo que, além da negligência médica, o dolo também se dá para constituir um acidente médico (3). Todavia, esta posição não faz nenhum sentido, por duas razões: por um lado, porque o Regulamento para o Tratamento de Acidentes Médicos prevê expressamente a negligência médica como um dos requisitos de acidente médico; por outro lado, porque o dolo faz com que a instituição médica e seus profissionais de saúde tenham responsabilidade civil e/ou criminal, caso sejam cumpridos os respetivos requisitos, não se constituindo um acidente médico.

Diferentemente do acidente médico, a responsabilidade civil médica exige a culpa que inclui não só a negligência médica, como também o dolo, mas na maioria das vezes o que ocorre é a negligência médica porque a ética médica exige aos profissionais de saúde 
atenderem aos seus pacientes como seus familiares (7). No que se refere à culpa, convém

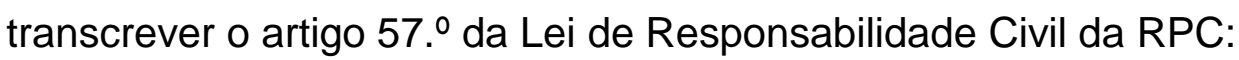

Durante o diagnóstico e tratamento médico, caso os profissionais de saúde não exerçam o dever de cuidar correspondente ao nível atual de tratamento médico e causem lesões ao paciente, a instituição médica em causa é responsável pela indemnização.

Desta disposição jurídica podemos entender que no ordenamento jurídico da RPC o critério para afirmar a culpa dos profissionais de saúde baseia-se em verificar se o seu dever de cuidar corresponde ou não ao nível atual de tratamento médico. No nosso entendimento, como entendem também alguns autores, esse nível atual de tratamento médico deve variar conforme a especialidade médica e urgência médica. Relativamente à especialidade médica, como numa instituição médica normalmente existem várias especialidades (por exemplo, pediátrica, ortopedista, obstetrícia e ginecologia, etc.), não podemos, nem devemos exigir o conhecimento de uma especialidade a que um médico não pertence e afirmar a sua culpa. No entanto, caso um médico que não tenha o nível de determinada especialidade insista em proceder ao tratamento desta especialidade, a sua culpa deve ser analisada conforme o nível desta mesma especialidade, com vista à proteção do interesse do paciente; ao invés, se um médico de determinada especialidade atuar como um médico geral, analisa-se a sua culpa conforme o dever de cuidar de um médico geral (6). No que concerne à urgência médica, a urgência de tratamento médico deve levar à redução do grau do dever de cuidar por parte dos profissionais de saúde porque durante a situação urgente não é possível exigir a um médico fazer, por exemplo, diagnóstico atempado ou observação cuidadosa ao paciente e ter uma capacidade suficiente de pensar, como se faz normalmente. Por outras palavras, ao analisar a culpa dos profissionais de saúde, deve atender-se, caso a caso, à proporcionalidade entre o grau de urgência e o grau do dever de cuidar. Contudo, há exclusão da culpa quando não é possível exigir que os profissionais de saúde em causa cumpram o dever de cuidar (6).

Há quem entenda que deve considerar-se também a territorialidade médica, no sentido em que, por um lado, existe diferença óbvia entre hospitais gerais e hospitais pequenos no que se refere aos equipamentos e profissionais de saúde, por outro lado, existe diferença entre hospitais de zona economicamente desenvolvida e hospitais de zona remota (6). Parece-me que este entendimento não deve ser acolhido, porque os 
profissionais de saúde ao entenderem que a sua instituição médica não tem as condições devidas para realização de determinados diagnósticos ou tratamentos médicos devem informar o paciente da necessidade de transferência para uma outra instituição médica com essas condições, em vez de insistência no tratamento médico que não seja muito útil ou tenha mais risco para o paciente.

Ademais, desde que haja culpa no tratamento médico por parte dos profissionais de saúde, a instituição médica a que pertencem tem, em simultâneo, culpa de seleção, gestão e educação, o que se trata da responsabilidade vicária (7). O que quer dizer que a existência da culpa dos profissionais de saúde presume a culpa da instituição médica na qual prestam serviços de saúde, bem como a sua responsabilidade quando sejam cumpridos também os outros requisitos exigidos. A responsabilidade vicária é entendida como aquela de que, caso exista certa relação especial entre o ator e o terceiro ou entre o ator e a vítima, o ator é responsável pelo ato do terceiro que viole os direitos da vítima (10). Desta definição entende-se que se salienta a responsabilidade de instituição médica pelo ato praticado pelos seus profissionais de saúde (11). Na altura, a adoção legislativa da responsabilidade completa de instituição médica teve a intenção de fortalecer a responsabilidade pelo dano causado ao paciente (11).

Para além do critério de afirmar a culpa dos profissionais de saúde e da consequente presunção da culpa da instituição médica, o artigo 58. a Lei de Responsabilidade Civil da RPC prevê ainda um mecanismo de presunção da culpa da instituição médica, a saber:

Presume-se a culpa da instituição médica caso sejam causados danos a um paciente em qualquer das circunstâncias seguintes:

(1) a instituição médica viola disposições de leis, regulamentos administrativos, regras ou outras especificações sobre diagnóstico e tratamento médico;

(2) a instituição médica esconde ou recusa a fornecer processos clínicos relacionados com a disputa;

(3) a instituição médica forja, falsifica ou destrói processos clínicos.

Sobre a primeira alínea do citado artigo, entende-se que a ilicitude, agora por parte da instituição médica, presume a sua própria culpa. Existem situações em que a instituição médica viola as disposições referidas na primeira alínea do artigo supra citado. Por exemplo, há um acórdão que entendeu que, tendo sido formalmente internado o paciente, a instituição médica que por falta de camas lhe pediu voltar para casa à espera da 
notificação teve culpa porque o paciente não podia ter diagnóstico profissional e tratamento adequado e, por causa disso, morreu6.

Sintetizando todo o exposto acima, entendemos que se presume a culpa da instituição médica por duas formas: primeira, a culpa dos profissionais de saúde presume a culpa da instituição médica em que prestam serviços de cuidados de saúde, conforme o regime da responsabilidade vicária; segunda, a ilicitude, por parte da instituição médica, presuma a sua culpa, conforme a primeira alínea do artigo 58.ำ da Lei de Responsabilidade Civil da RPC.

\section{Do Dano}

Da definição do acidente médico entendemos que se exige lesão pessoal causada ao paciente, isto é, danos causados no paciente. Conforme a seriedade de lesão pessoal, o acidente médico pode ser classificado em quatro categorias. Para o efeito, convém transcrever o artigo 4.. do Regulamento para o Tratamento de Acidentes Médicos:

Os acidentes médicos são classificados em quatro categorias de acordo com a seriedade de lesões pessoais causado ao corpo do paciente:

Grau I de acidentes médicos: aqueles que tenham causado morte ou incapacidade séria do paciente;

Grau II de acidentes médicos: aqueles que tenham causado incapacidade de nível médio ou lesão nos órgãos que leva a sérios obstáculos funcionais;

Grau III de acidentes médicos: aqueles que tenham causado incapacidade de nível suave ou lesão nos órgãos que leva a gerais obstáculos funcionais;

Grau IV de acidentes médicos: aqueles que tenham causado lesão óbvia no corpo de pacientes ou outras consequências.

O critério para os específicos graus é formulado pelo departamento responsável pela saúde do Conselho Estadual.

Desta norma jurídica, bem como do Critério para Classificação do Acidentes Médicos (Criterion for Classification of Medical Accidents) que prevê as várias situações para cada grau de acidentes médicos, podemos confirmar que a lesão pessoal inclui apenas a lesão causada no corpo de paciente com determinado grau, não contendo a lesão patrimonial

\footnotetext{
${ }^{6}$ Acórdão n.ำ (2017)兵08民终198号, do Tribunal Popular Intermediário (新疆生产建设兵团第八师中级人民法院), de 5 de Abril de 2017. http://0-www.pkulaw.cn.umaclib3.umac.mo/Case/pfnl_1970324846026016.html?match=Exact (acesso em 12 de Setembro de 2017).
} 
nem a lesão mental. A lesão de integridade física que não tenha o mínimo grau legalmente previsto não pode ser o dano que constitui o acidente médico (4), mas pode ser o dano que constitui a responsabilidade civil médica nos termos da Lei de Responsabilidade Civil da RPC. Por outro lado, as lesões patrimoniais e mentais são consequências resultantes da lesão causada no corpo de paciente e, logo, não podem ser danos que constituam o acidente médico, mas podem ser danos que constituem a responsabilidade civil médica (9). Contudo, há autor que defende que as lesões pessoais no âmbito de acidente médico podem incluir também as lesões patrimoniais e lesões mentais (5).

Ao contrário do que ocorre no âmbito do acidente médico, os danos que o regime da responsabilidade civil médica exige são mais abrangentes, incluindo não só a lesão de integridade física, como também as lesões patrimonal e mental (7). Portanto, é fácil entender que podem ocorrer danos que nem necessitam de ser lesão de integridade física, como o não respeito do consentimento informado do paciente, isto é, violação do direito à autodeterminação do paciente.

\section{Do nexo de causalidade}

O nexo de causalidade implica que existe uma relação de causa e de resultado entre o ato médico lícito e o dano causado, aplicando-se quer ao acidente médico quer à responsabilidade civil médica. Na doutrina chinesa, a teoria que se aplica no que se refere ao nexo de causalidade é a teoria da causalidade adequada (ou relativa), quer para o acidente médico (17), quer para a responsabilidade civil médica (7). Esta teoria significa que o ato médico ilícito é uma condição adequada e indispensável para a ocorrência dos danos causados (17).

No âmbito do acidente médico, há autores que defendem ainda a teoria da causalidade indireta (4) (9) (18), no sentido em que o ato é uma condição indireta para a ocorrência dos danos originados, como por exemplo a transfusão sanguínea é uma condição indireta para a ocorrência das consequências adversas e neste caso há nexo de causalidade indireta entre o fornecimento de sangue por parte da instituição fornecedora e as consequências adversas, bem como nexo de causalidade direta entre 0 ato de transfusão sanguínea por parte da instituição médica e as mesmas consequências adversas (9). 


\section{Instituição médica e profissionais de saúde como sujeitos}

Quer no âmbito do acidente médico quer no âmbito da responsabilidade civil médica, exigem-se a instituição médica e seus profissionais de saúde como sujeitos. A instituição médica é aquela que obtém a licença de prática de instituição médica com certa categoria nos termos dos artigos 2..$^{\circ}$ e $3 .^{\circ}$ das Regras Detalhadas para a Implementação do Regulamento para a Administração de Instituições Médicas (Detailed Rules for the Implementation of the Regulation on the Administration of Medical Institutions), enquanto os profissionais de saúde são aqueles que possuem certificado de qualificação e permissão de prática (4). A instituição ou os indivíduos, que não tenham respetivamente a licença exigida ou o certificado de qualificação e permissão de prática, cometem prática médica ilegal, que pode ser imputada com a responsabilidade civil e/ou responsabilidade criminal, nos termos do artigo $61 . .9$ do Regulamento para 0 Tratamento de Acidentes Médicos.

Sobre os profissionais de saúde, há quem defenda que os profissionais de saúde incluem ainda pessoal de serviços logísticos e de gestão médica, para além daqueles que tenham certificado de qualificação e permissão de prática (5) (16) (19). Contudo, este entendimento não me parece adequado porque quem realiza determinado diagnóstico ou tratamento médico é o médico responsável e, havendo, outros médicos participantes, pelo que, em caso de ocorrência de danos causados ao paciente, é apenas esses médicos que têm a respetiva responsabilidade. O pessoal de serviços logísticos e de gestão médica que só desempenha um papel de auxílio ou de gestão hospitalar não participam diretamente no diagnóstico ou tratamento médico. Caso esse pessoal, por si só, cause danos ao paciente, o que se trata não de acidente médico nem de responsabilidade civil médica, mas sim de responsabilidade civil ou/e criminal em geral, ao abrigo dos Princípios Gerais do Direito Civil da RPC (General Principles Of the Civil Law Of the People's Republic Of China) ou do Direito Penal da RPC (Criminal Law of the People's Republic of China).

\section{Considerações finais}

Pelo exposto, embora a Lei de Responsabilidade Civil da RPC não revogue as normas juridicas de natureza civil do Regulamento para o Tratamento de Acidentes Médicos, na doutrina chinesa entende-se que este regulamento perdeu a sua natureza 
civil, mantendo apenas a natureza administraiva para efeitos de sancionamento à instituição médica e seus profissionais de saúde infratores. Mesmo assim, ainda surge a questão de saber se a constituição de acidente médico é um pressuposto da responsabilidade civil médica prevista na nova lei e o presente texto concluiu e deu uma resposta negativa.

Tendo um regime novo sobre a responsabilidade civil médica previsto na nova lei, convém ainda analisar se esse regime novo e o regime de acidente médico têm os mesmos requisitos e se cada um destes tem o mesmo âmbito. O presente texto concluiu que os dois regimes têm os mesmos requisitos (isto é, facto ilícito, negligência médica ou culpa, dano, nexo de causalidade e instituição médica e profissionais de saúde como sujeitos), mas alguns destes têm âmbito diferente, como sucede na ilicitude, na negligência médica ou culpa e no dano.

Para que haja uma melhor harmonia nos dois regimes juridídicos, ambos agora dos diferentes diplomas legais, sugere-se que sejam revogadas as normas relativas à responasbilidade civil médica (isto é, Capítulo V Compensações para Acidentes Médicos) do Regulamento para o Tratamento de Acidentes Médicos, com vista a evitar confuções existentes nos dois regimes jurídicos.

\section{Referências}

1. Wang HL. Restudy on the Characteristics of Medical Accident. Tribune of Political Science and Law. 1987; 4: 24-30.

2. Wang XB, Analysis on Identification and Prevention of Medical Accident. Harbin Medical Journal. 2014; 3: 169-170.

3. Yang L, Li Y. 医疗事故认定的法律思考. Business China. 2010 Jun.; 200: 146-147.

4. Wu ZY, Zhao YS, Tan QP. 损害赔偿法律精要与依据指引. China: People's Publishing House; 2005. 
5. Tian XF, Zhang JH. 试论医疗事故的构成要件. Inheritance \& Innovation. 2010; 4: 140-141.

6. Wang QL. Discussion on Particularity of Behavior of Medical Negligence. The Chinese Health Service Management. 2006; 7: 413-414.

7. Yang LS. Medical Injury Liability Law. Beijing: Law Press; 2012.

8. Wang LM. 侵权责任法研究(volume II). Beijing: China Renmin Unversity Press; 2011.

9. Yang WJ. On the Formation of Medical Accidents. Journal of Political Science and Law. 2003 Abril; 20 (2): 35-37.

10. Zhang MA. 替代责任的比较研究. Journal of Gansu Political Science and Law Institute. 2009 Setembro; 5: 50-58.

11. Yang B. Public Policy,Medical Behavior and Duty: An Observation of Medical Malpractice Liability. Modern Law Science. 2011 Setembro; 33 (5): 184-193.

12. Liu Y, Yin SY, Chen Q. Redefinition of the Concept of Medical Malpractice after the Implementation of the Tort Liability Law. Chinese Academy of Medical Science. 2012 Março; 20 (2): 55-57.

13. Cheng JG. 与医疗事故技术鉴定程序有关的几个问题. Tibetan Journal of Medicine. $2004 ; 25(1): 41-44$.

14. Liu Z. 疏忽大意的過失與過于自信的過失刑罰區分之必要. Legal System and Society. 2012; 34: 260-261.

15. Yang LS. Tort Liability Law. Beijing: Law Press; 2011.

16. Ni HL, Liu XL. 论医疗事故构成要件. Med J Qilu. 2005 Junho; 20 (3): 267-268.

17. Jian N. 医疗事故中医疗行为与损害后果之间的因果关系. Journal of Henan Medical College for Staff and Workers. 2007 Outubro; 19 (5): 504-505.

18. Chen JX. An Analysis of Problems Relevant to the Appriaisal of Faulty Medical Treatment. Journal of Fujian Medical University (Social Science Edition). 2006 Setembro; 7 (3): 22-24. 
19. Wang R. 论我国医疗损害责任. Journal of HuBei TV University. 2014 Março; 34 (3): 84-85.

20. Yang HY. 医疗损害责任的构成要件及法律适用. Culture and History Vision(Theory). 2010 Outubro; 74-77.

Recebido em: 13.8.2017 Aprovado em:17.9.2017 